\title{
Emergency Landing Automation Aids: An Evaluation Inspired by US Airways Flight 1549
}

\author{
Ella M. Atkins.* \\ University of Michigan, Ann Arbor, Michigan, 48105, U.S.A
}

\begin{abstract}
The Hudson River emergency landing of US Airways Flight 1549 inspired aviation enthusiasts and citizens alike. The pilot's skill and composure were exceptional, clearly contributing to one of the most successful aircraft water ditchings possible. As we prepare for transition to a next-generation air transportation system, we are developing new technologies both to increase system capacity and efficiency and improve safety levels. This paper describes the practical application of an adaptive flight planning automation aid to the specific US Airways loss-of-thrust situation, demonstrating how this technology, if available, could have enabled a safe return to a LaGuardia runway. First, the adaptive flight planning architecture and its evolution are summarized, followed by an analysis of the Flight 1549 cockpit data recording time histories to identify pertinent features for our analysis. The adaptive flight planner was tasked with identifying emergency no-thrust landing plans for the A320 at a series of different delay times after the dual bird strike incident occurred. Our results show that LaGuardia airport runways were reachable so long as the approach is initiated within approximately sixteen seconds after the dual bird strike incident. This result is consistent with accident docket data published by the NTSB. Our results further illustrate how chances of a safe runway landing decrease as a function of delay, in this case due to being forced to land on a runway with suboptimal wind conditions, or ultimately being forced into a water ditch situation that may not always have the positive result of Flight 1549. Our adaptive flight planning software, written in $\mathrm{C}$, computes landing flight plans in under a second on a single-core PC with no changes in this work from a pre-2009 implementation beyond $\mathbf{A} 320$ glide parameters. With sub-second real-time response, an emergency landing plan can be presented to the pilot just as he/she is beginning to consider options, maximizing the efficiency with which the plan can be executed. Further, with datalink capability, emergency flight plan information can be disseminated throughout the local air traffic network to maximize coordination efficiency.
\end{abstract}

\section{Introduction}

$\mathrm{O}$ January 15, 2009, US Airways Flight 1549 was struck by Canadian Geese soon after takeoff from New York’s

La Guardia airport, losing thrust in both engines. The ensuing emergency glide into the Hudson River was highly successful: the airframe remained intact and all occupants escaped without injury. The result, popularized as "Miracle on the Hudson", ${ }^{1}$ was a testament to the skill of the flight crew and robustness of the A320/Q airframe. Examination of this incident can lead to two diverse conclusions with respect to the role of cockpit crew and automation. On one hand, the ingenuity and quick adaptation displayed by the US Airways crew is a clear example of human pilot value, especially with the level of skill and composure exemplified throughout the Flight 1549 incident. On the other hand, accurate and rapid computation of glide (engine-out) trajectory to a local airport (e.g., return to LaGuardia) and communication of emergency intent to air traffic management via high-speed datalink might have "changed history" by facilitating an unremarkable emergency landing in which the occupants were still unharmed and the airframe was not further damaged.

\footnotetext{
*Associate Professor, Aerospace Engineering Department, University of Michigan, Ann Arbor, MI, Associate Fellow.
} 
When an emergency such as the Flight 1549 situation occurs, reaction must be swift and accurate. First, the plane must be stabilized, and then a decision must be made of how to best handle the emergency. Certainly, when thrust is lost, the plane must land. At low altitude, time is of the essence. Captain Chelsey Sullenberger summarized his decision-making process for Flight 1549 during his testimony on this incident as follows: ${ }^{2}$

"The first option, of course, was to return to LaGuardia. I took a look out the left window at the landmarks, at the distance remaining from where we were to LaGuardia, and the fact that we were already at low altitude, at low air speed, heading away from the airport, and when I took control of the airplane with the airplane still in a climb attitude but without the climb thrust in the airplane, our air speed began to decay rapidly. In order to lower the nose and retain a safe flying speed, our rate of descent necessarily increased dramatically. Looking at where we were and how much time, altitude, and distance would be required to turn back toward LaGuardia and then fly toward LaGuardia, I determined quickly that that was going to be problematic, and it would not be a realistic choice, and I couldn't afford to be wrong. Once I had turned toward LaGuardia, it would have been an irrevocable choice, eliminating all other options. I had to make sure I could make it before I chose that option. I decided I couldn't. ... And, as to Teterboro, it was too far away. The only option remaining, the only place in a highly developed, metropolitan area, long enough, wide enough, smooth enough to land was the river."

The decisions of Captain Sullenberger were wise. As highlighted above he indicated "I had to make sure I could make it [back to LaGuardia] before I chose that option. I decided I couldn't." The Airbus A320 has an extensive and advanced avionics system, but in case of anomalous situations such as that experienced by Flight 1549, control and decision-making revert to the pilot. The goal of this paper is to link emergency flight planning algorithms, designed to be intuitive, provably-correct, and computationally-tractable, with this US Airways incident, to show how cockpit automation can improve safety through its proliferation into NextGen cockpits and onto NextGen datalinks. This idea is not unique to this paper. In his book focusing on the US Airways incident, aviation author Langewiesche calls for just such automation tools: ${ }^{1}$

"The Airbus computer system [in Flight 1549] knew how high above the ground the airliner was, knew about the obstacles and terrain in the area, and knew where the nearby airports were and what runways they had. The computer system also continuously calculated the wind speed and direction by comparing airspeed and groundspeed, heading and track over the ground. The computer system could easily have been programmed with the gliding capabilities of the A320. Did it offer any suggestions about the nearest glidable airport and runway? Did it highlight those airports in a special color on the moving map? No. The US Airways crew's most difficult decision was whether to try to make it back to LaGuardia or to land offairport and the Airbus computer system provided no help."

Although the above quote focuses on Airbus, there are no commercial transports equipped with avionics that will compute a full emergency landing plan even for loss-of-thrust situations for which aerodynamic and sensing properties are unchanged. Moving map GPS systems do show nearby runways, but the pilot is left with the task of computing a path to these runways, potentially in a few seconds as was the case with Flight 1549.

Over the past 10 years we have developed an adaptive flight planning (AFP) architecture to help flight crews safely land a disabled aircraft. Our early work ${ }^{3,4}$ focused on the "dynamically-straightforward" case of total loss of thrusting power, the situation experienced by US Airways Flight 1549 and a primary cause in a non-trivial number of single-engine general aviation incidents each year. ${ }^{5}$ Subsequently, we have addressed adaptive or emergency flight planning in a variety of other failure and damage situations, ranging from control surface jams ${ }^{6}$ to severe structural damage ${ }^{7}$. Although we have worked with search-based trajectory optimization algorithms, we emphasize use of analytic solutions such as the Dubins path ${ }^{8}$ extended to 3D, recently extended to analytically solve for landing paths in cases in which straight flight is no longer possible. ${ }^{9}$ Other researchers have also proposed emergency flight planning with degraded performance, starting with early work that proposed such automation aids in the context of improving pilot situational awareness. ${ }^{10,11}$ 
This paper will present the application of our adaptive flight planning (AFP) architecture to the US Airways Flight 1549 situation. Below, our AFP architecture is reviewed, focusing on the first generation system initially designed to handle loss-of-thrust situations thus adopted for this paper. We summarize the automated landing site selection and Dubins-based path planning algorithm applied to Flight 1549 but published previously. ${ }^{4}$ Next, flight data recorder (FDR) data from Flight 1549 is analyzed to enable a realistic transcription of the Flight 1549 situation into our adaptive flight planner. We then present a sequence of AFP solutions identified for Flight 1549, at different times after the incident occurred, both to evaluate a series of AFP solutions and to examine the impact of delay in response on landing options. Of particular note is that, although we altered our models to better reflect A320 glide performance, we did not need to upgrade our existing AFP software, coded in C in 2004-2005. This provided us with a rare opportunity to assess the performance of our AFP on a real-world example, as well as to compare our results with the results obtained from the extensive investigation of the Flight 1549 incident. ${ }^{12,13,14,15}$ Given starting waypoint and wind conditions derived from Flight 1549 flight data, we ask our automation aid to identify all reachable runways given [steady] wind conditions and glide constraints for the A320. A waypoint-based trajectory is then identified to the top-priority landing site, or other reachable alternative as needed. We discuss the implications of the AFP automation aid in the context of Flight 1549 cockpit voice recorder (CVR) and NTSB analyses, recommending emergency flight plan data be made available on the next-generation air transportation network (datalink) as a means of high-speed traffic coordination in an emergency. We then briefly summarize our findings and future work required for AFP certification and ultimate adoption.

\section{Adaptive Flight Planning Architecture}

Two generations of adaptive flight planning architectures has been developed, with the original and simplest used to generate the results shown in this paper. The first generation architecture, ${ }^{3,4}$ shown in Figure 1, has two primary components: landing site search and post-failure trajectory planning. The second generation architecture, also containing modules to discover post-anomaly performance and adapt autonomy level, is not discussed further as its additional capabilities are not used in this paper. In the baseline AFP, a landing site search (LSS) module selects a feasible and desirable final state (landing runway) that takes into account the post-failure aircraft performance envelope. The trajectory planner then defines a waypoint-based trajectory connecting initial aircraft state (latitude $x$, longitude $y$, altitude $h$, heading $\psi$, velocity $V$ ) with the desired touchdown state at the landing runway's approach end. The AFP architecture and LSS components are general for any failure; however, the trajectory planner must efficiently meet the spectrum of reduced performance scenarios. We have in previous work adopted two trajectory planning approaches for the AFP: a highly-efficient waypoint generation algorithm (WGA) $(<1$ second execution time) customized to loss-of-thrust emergencies $\left(\gamma_{\max }<0\right)$, and a trim database approach that builds a sequence of valid post-failure trim states connecting the aircraft with the designated landing runway. Although this paper focuses on the loss of thrust case (thus the WGA), the trim database approach has also been implemented and is being extended to cover a suite of control surface jam and structural damage scenarios. Figure 2 shows the landing site search (LSS) algorithm developed for our first generation architecture - this algorithm is straightforward, but we believe this is a desirable property given the real-time decision-making time constraints observed for Flight 1549. Inputs to LSS include a US airport database, updated performance model, initial state, forecast winds over different flight levels (FL), and airport weather conditions. The LSS outputs a list of viable landing runways ranked according to a safety-oriented utility function, after which a segmented landing trajectory is planned for the top-ranked runway. The AFP is implemented in C and executes from start to finish in under a second on a single-core PC.

As described in more detail in our previous publications, the LSS footprint for loss of thrust is estimated in real-time by propagating best-glide paths in primary flight directions. Runways within this footprint are classified as reachable, and are prioritized by the multi-objective utility function:

$$
U=\sum_{i} C_{i} \cdot w_{i}=C_{1} \cdot \frac{r_{l}}{r_{l, \max }}+C_{2} \cdot \frac{r_{w}}{r_{w, \max }}+C_{3} \cdot q_{I}+C_{4} \cdot\left(\frac{d}{d_{\max }}\right)+C_{5} \cdot \frac{w_{h}}{w_{h, \max }}+C_{6} \cdot \frac{\left(w_{c, \max }-w_{c}\right)}{\left(w_{c, \max }-w_{c, \text { min }}\right)}+C_{7} \cdot q_{S}+C_{8} \cdot q_{f}
$$




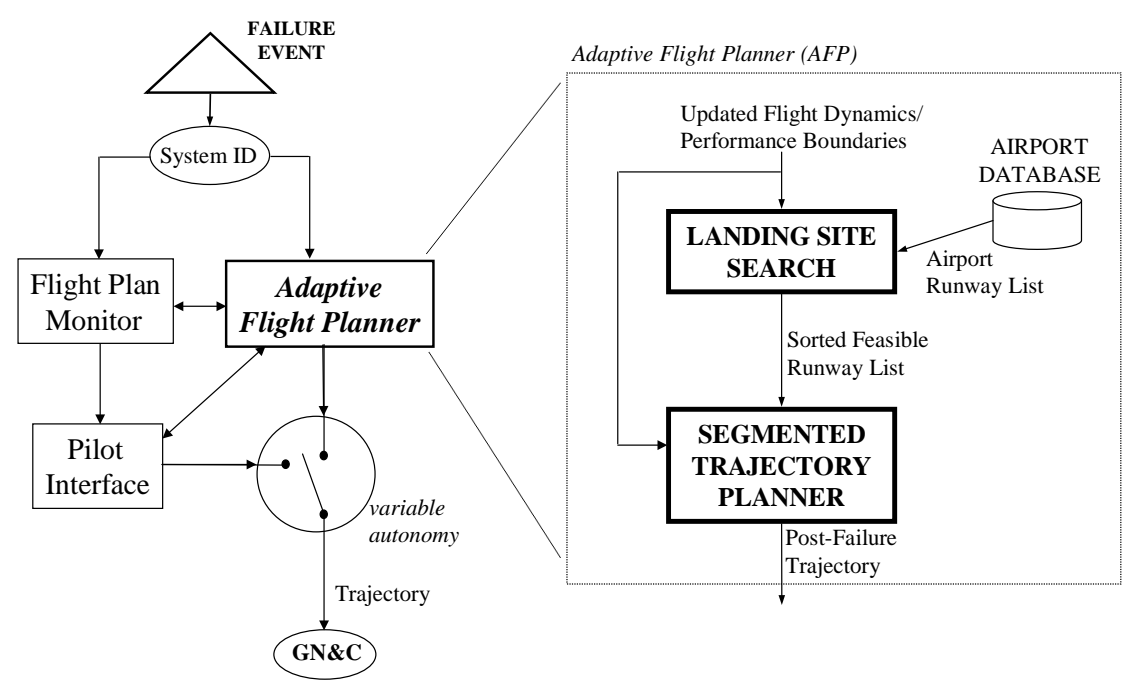

Figure 1: First-Generation Adaptive Flight Planning (AFP) Architecture. ${ }^{4}$

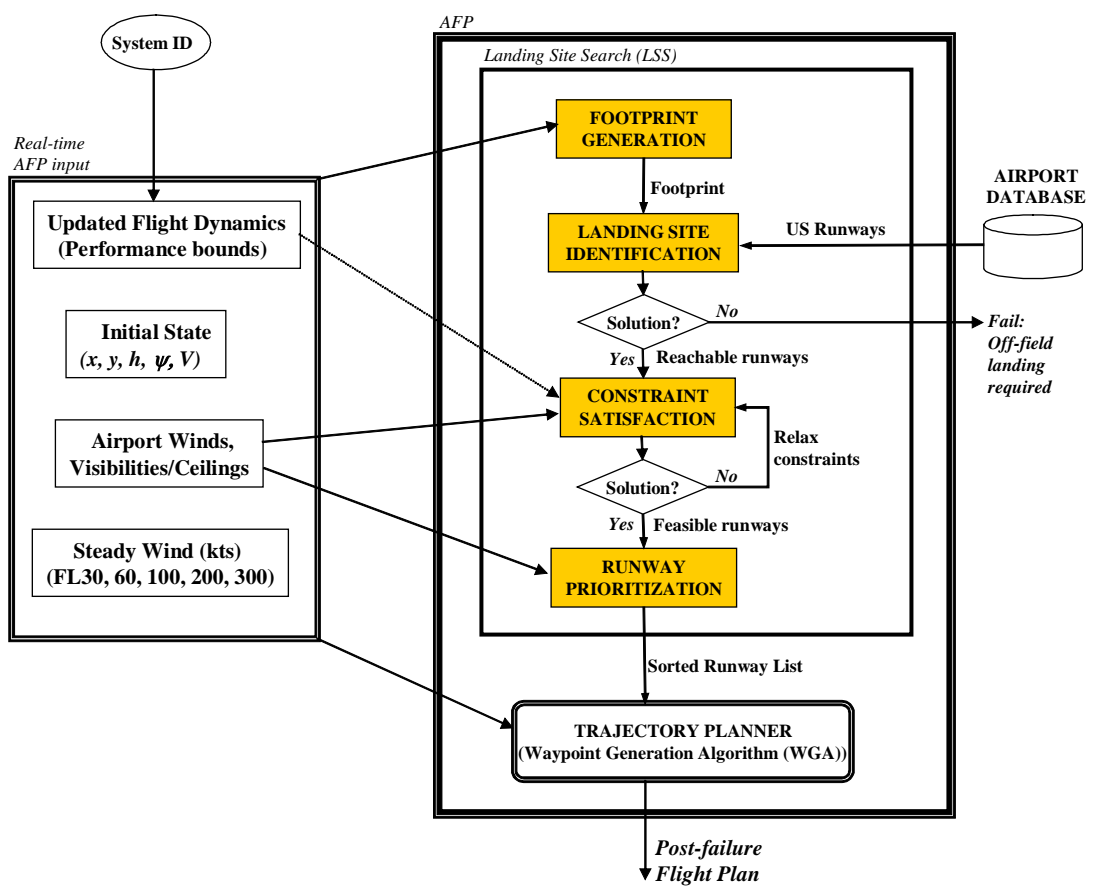

Figure 2: Landing Site Search (LSS) Procedure. ${ }^{4}$

This equation includes runway length $r_{l}$, runway width $r_{w}$, instrument approach quality $q_{I}$, distance $d$ from the footprint boundary, headwind velocity $w_{h}$, crosswind velocity $w_{c}$, surface quality $q_{s}$, and facility availability measure $q_{f}$. Numerical costs $r_{l}, r_{w}, d, w_{h}$, and $w_{c}$ are normalized by their extreme values over the set of feasible landing sites to guarantee individual cost values in the range [0.0 1.0]. The majority of the Eq. (1) parameters increase safety margins during landing, while facility quality $q_{f}$ is a convenience preference that favors landing where the aircraft can be repaired. Distance parameter $d$ gives preference to runways away from footprint boundaries, which indicates they likely fall well within maximum range and/or time constraints. Weighting factors $C_{i}$ are set to $\left\{C_{1}, C_{2}, \ldots, C_{8}\right\}=$ $\{0.15,0.15,0.15,0.15,0.1,0.1,0.1,0.1\}$ by default. Exact quality measure values and utility weighting factors 
would ultimately be based on expert knowledge, although to-date the selected weightings have generated acceptable runway choices as will be discussed for Flight 1549 below.

A standard rigid body steady flight model is used to represent aircraft performance. The Waypoint Generation Algorithm (WGA), detailed further in Atkins et al, ${ }^{4}$ first computes a minimum-length best-glide Dubins path to the selected landing runway. If this solution is feasible, it then constructs the detailed trajectory; if this solution is not feasible, it moves to the next runway on the prioritized list until no more runways within the footprint are available, in which case no runway landing is possible (at least, no runway landing is possible with a segmented steady flight trajectory). The Dubins solution is adjusted, either by extending final approach or inserting an s-turn, to accommodate maximum steepness constraints on flight path angle. Since the true Dubins path represents the minimum-length lateral traversal, no solution is possible when the initially-computed Dubins path is too long to meet maximum flight path angle constraints. In our AFP, turning radius is adjusted as a function of atmospheric density, based on steady flight parameters for the aircraft and a designated glide speed.

\section{Analysis of the Flight 1549 Flight Data}

Flight 1549 FDR data, ${ }^{13}$ available as a comma-separated variable file on the NTSB accident docket website, was processed to determine parameters required for the AFP to emulate the Flight 1549 situation. Results were compared with an NTSB flight performance analysis ${ }^{14}$ to verify data was being processed and interpreted accurately. We scaled the Eastern Standard time values provided in the FDR to a start time (0 seconds) just before the takeoff roll began to a final time of 343 seconds, just before impact on the Hudson. Data acquisition rates on the FDR range from 1 to 4 seconds, with GPS points stored only at 4 second intervals. To start, we examined the engine data since loss-of-thrust was the source of the emergency. Figure 3 shows the commanded and actual engine RPM (\%). Note that both engines had similar profiles so only Engine 1 from the FDR is shown here. At a time of approximately 127 seconds, the actual engine thrust is observed to dramatically drop, although not quite to zero. As shown in the engine command (blue) trend, the pilot temporarily drops the throttle to idle as part of the descent procedure, but realizes (as mentioned in the CVR transcript) that a small amount of thrust remains available. In our calculations, however, we take the conservative view of no thrust availability, since it is unclear how engine RPM translates to thrust in the damaged engines.

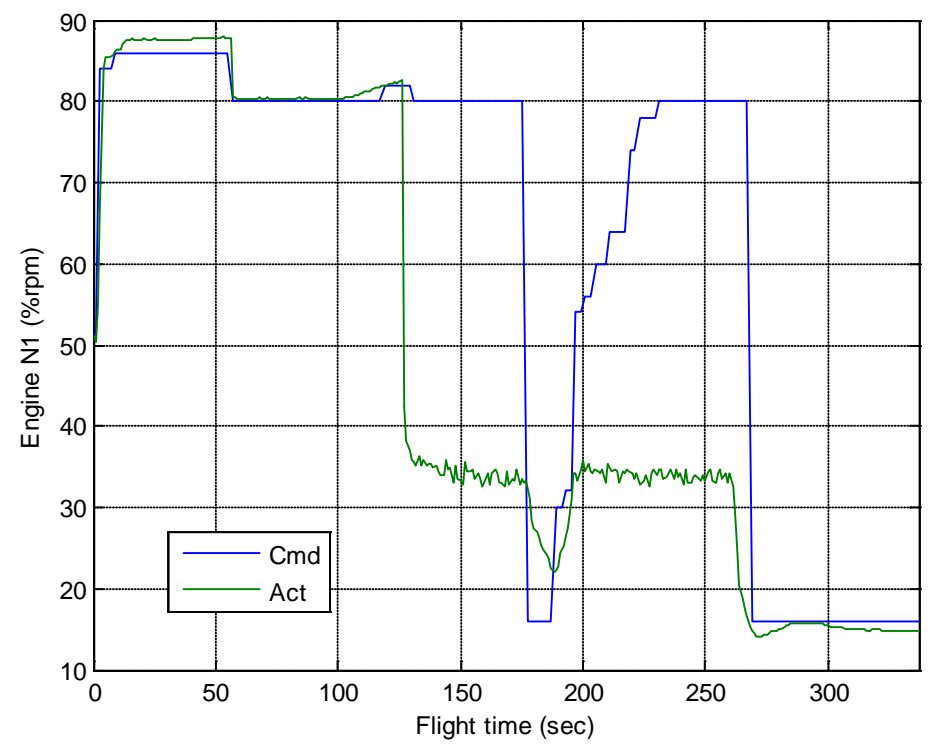

Figure 3: Engine (N1) Commanded and Actual RPM (\%) Time Histories (from Flight Data). 
Figure 4 shows the altitude, airspeed, and angle of attack time histories for Flight 1549. Although airspeed dips just after the bird strikes, the pilot responded quickly and the aircraft did not stall. Maximum altitude occurs when the pilot reacts to the decreasing airspeed, seconds after the incident. For completeness we show all three sources of altitude data in the Figure 4 plot. We use the maximum altitude time point in FDR data as our "loss-of-thrust detection" reference. Conservatively, delays in response are then computed with respect to this maximum-altitude time point. Because we use zero thrust, our best glide airspeed is lower (160 knots); we do not model the deceleration from the initial state at 200 knots, over which we could gain or at least maintain altitude, again resulting in a conservative translation for our analysis. Maximum altitude is just above $3000 \mathrm{ft}$, providing little time to select and execute the emergency approach to landing.
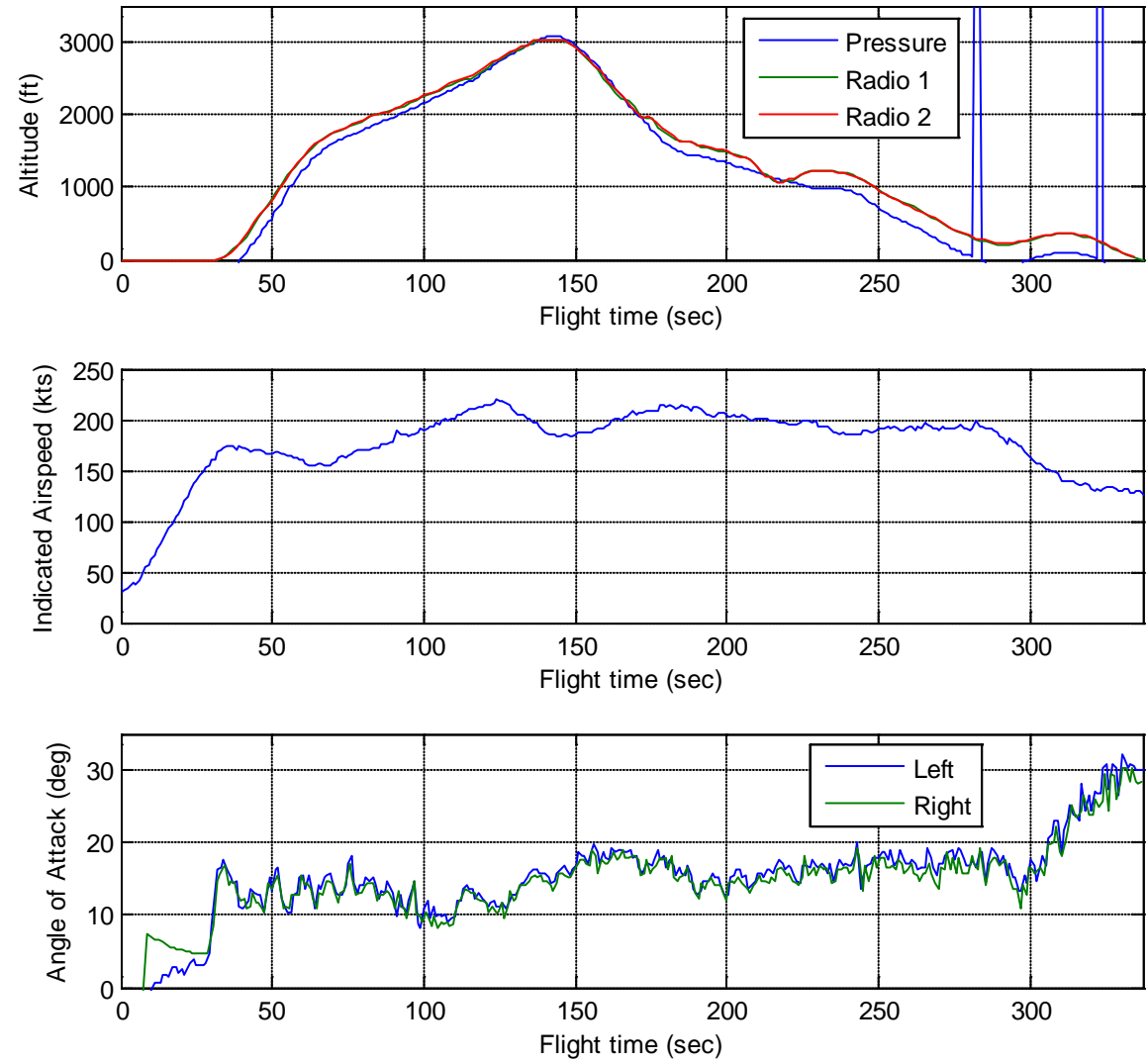

Figure 4: Altitude, Airspeed, and Angle of Attack Time Histories (from Flight Data).

Figure 5 shows heading, pitch, and roll attitude during the flight. Again, the plots indicate the pilot maintained control of the aircraft at all times. Although magnetic heading was stored on the FDR, all data was converted to true heading for consistency with inertial trajectory calculations. Figure 6 shows the ground speed, wind speed, and wind direction data from the FDR. The wind speed was relatively steady, averaged to be 13.4 knots at 320 degrees for our adaptive flight planning analysis. Figure 7 shows the three-dimensional acceleration of the aircraft, again indicating that stable flight control was maintained throughout. The only remarkable event is in longitudinal acceleration, with a drop in acceleration coinciding with the dual bird strike event and an increase in vertical acceleration to 1.3 g's during the 30-35 degree bank turn to align with the Hudson River. Figure 8 shows the control actuation commands. Nothing remarkable is noted here; flaps were retracted prior to the bird strikes and lowered prior to landing. The most rudder action occurred during takeoff, as is typical.

Figures 9 and 10 show the trajectory of Flight 1549, in 2-D and 3-D, respectively, from takeoff through touchdown. The point after the maximum altitude GPS FDR data point is marked in Figure 10, representing our initial state for the "fastest response" case labeled " $\mathrm{t}+4$ " seconds. The two subsequent points in the Figure 10 plot are labeled " $\mathrm{t}+8$ 
sec" and " $t+12 \mathrm{sec"} \mathrm{in} \mathrm{our} \mathrm{case} \mathrm{study.} \mathrm{As} \mathrm{shown} \mathrm{in} \mathrm{these} \mathrm{plots} \mathrm{and} \mathrm{later} \mathrm{discussed} \mathrm{in} \mathrm{the} \mathrm{context} \mathrm{of} \mathrm{the} \mathrm{CVR,} \mathrm{the}$ pilot initiated a left turn toward the Hudson, potentially influenced by an air traffic control to maintain heading 220, a course that traveled away from LaGuardia.
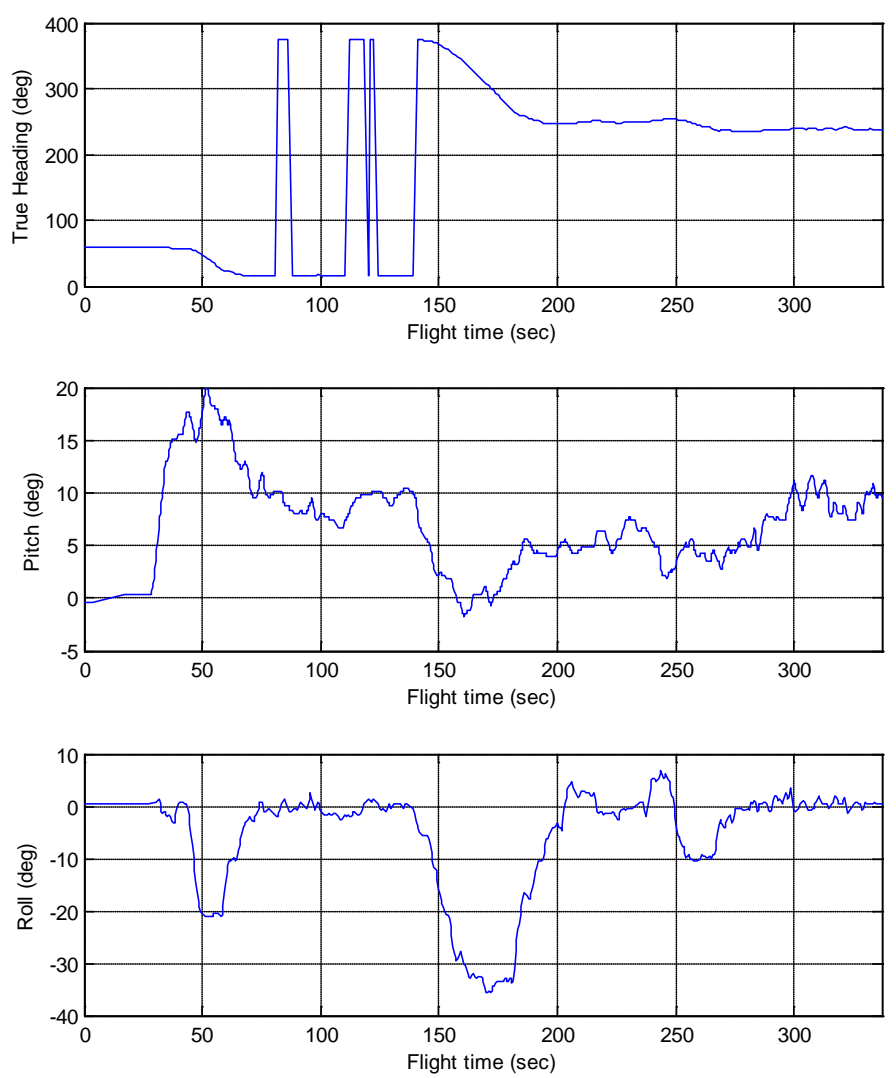

Figure 5: Aircraft Attitude Time Histories (from Flight Data).
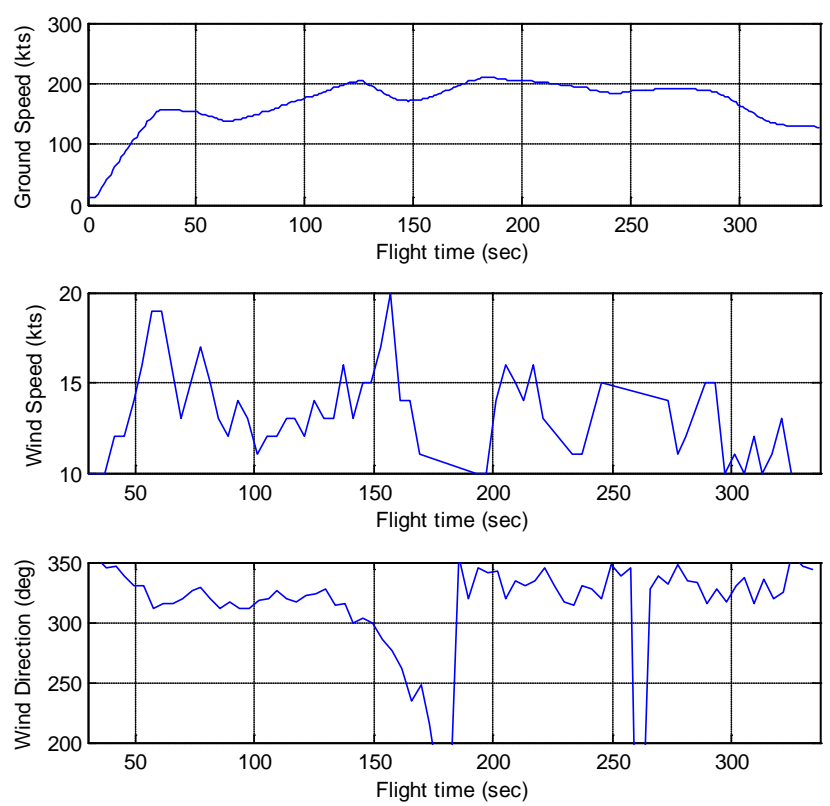

Figure 6: Ground and Wind Speed Time Histories (from Flight Data). 

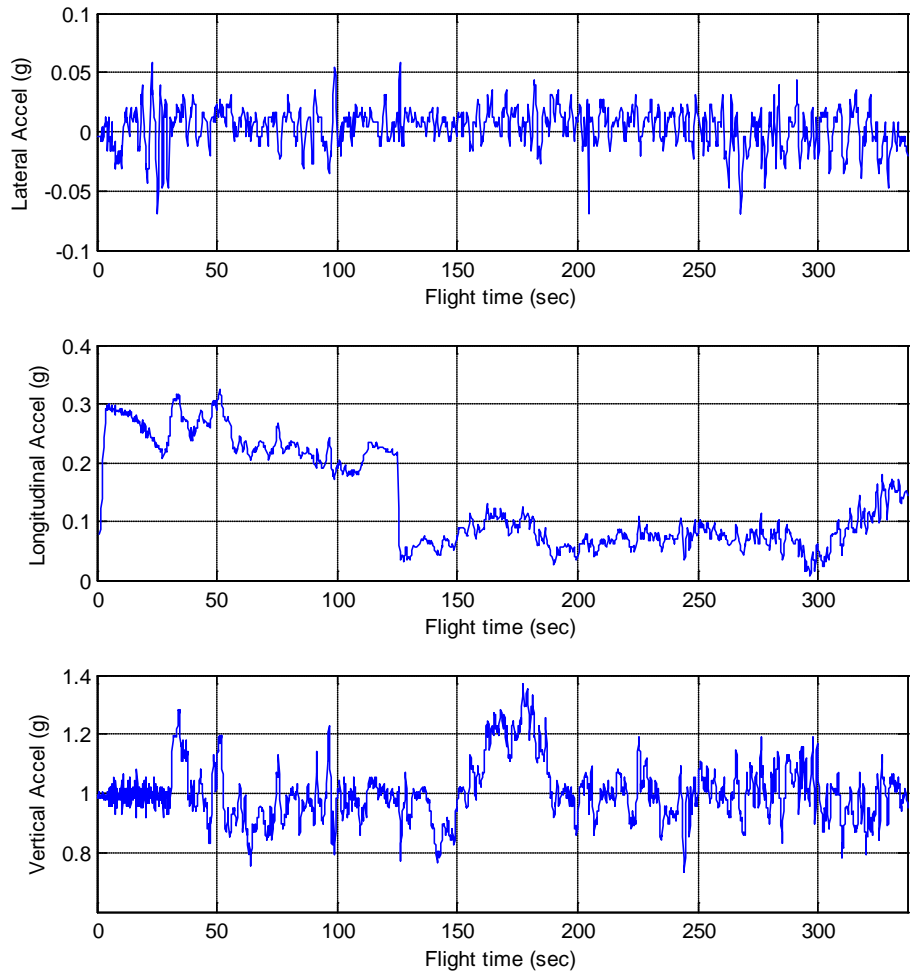

Figure 7: Acceleration Time Histories (from Flight Data).
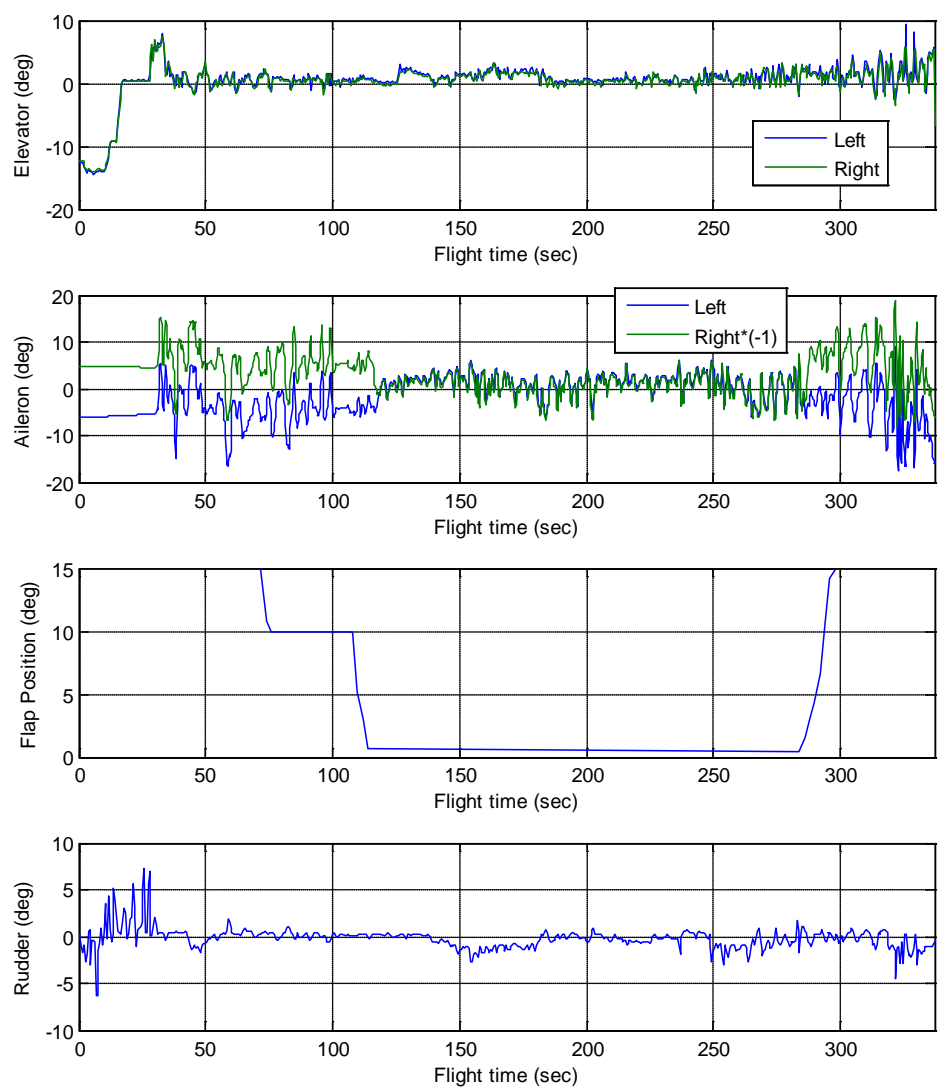

Figure 8: Control Surface Deflections (from Flight Data). 


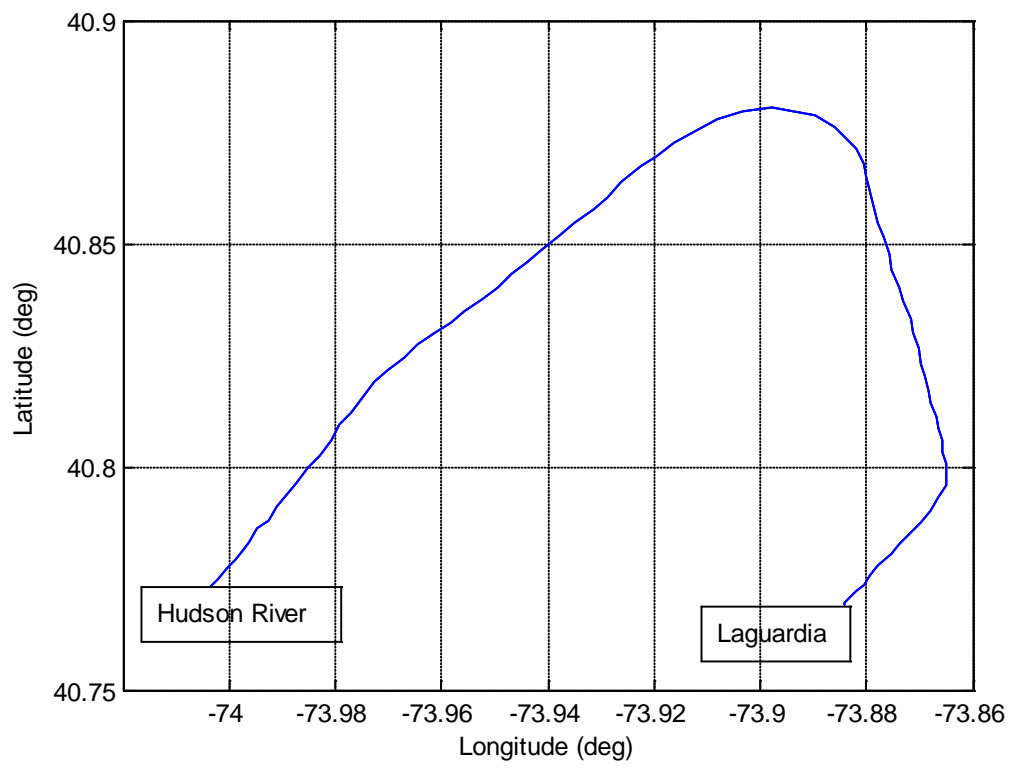

Figure 9: 2D Trajectory Profile (from Flight Data).

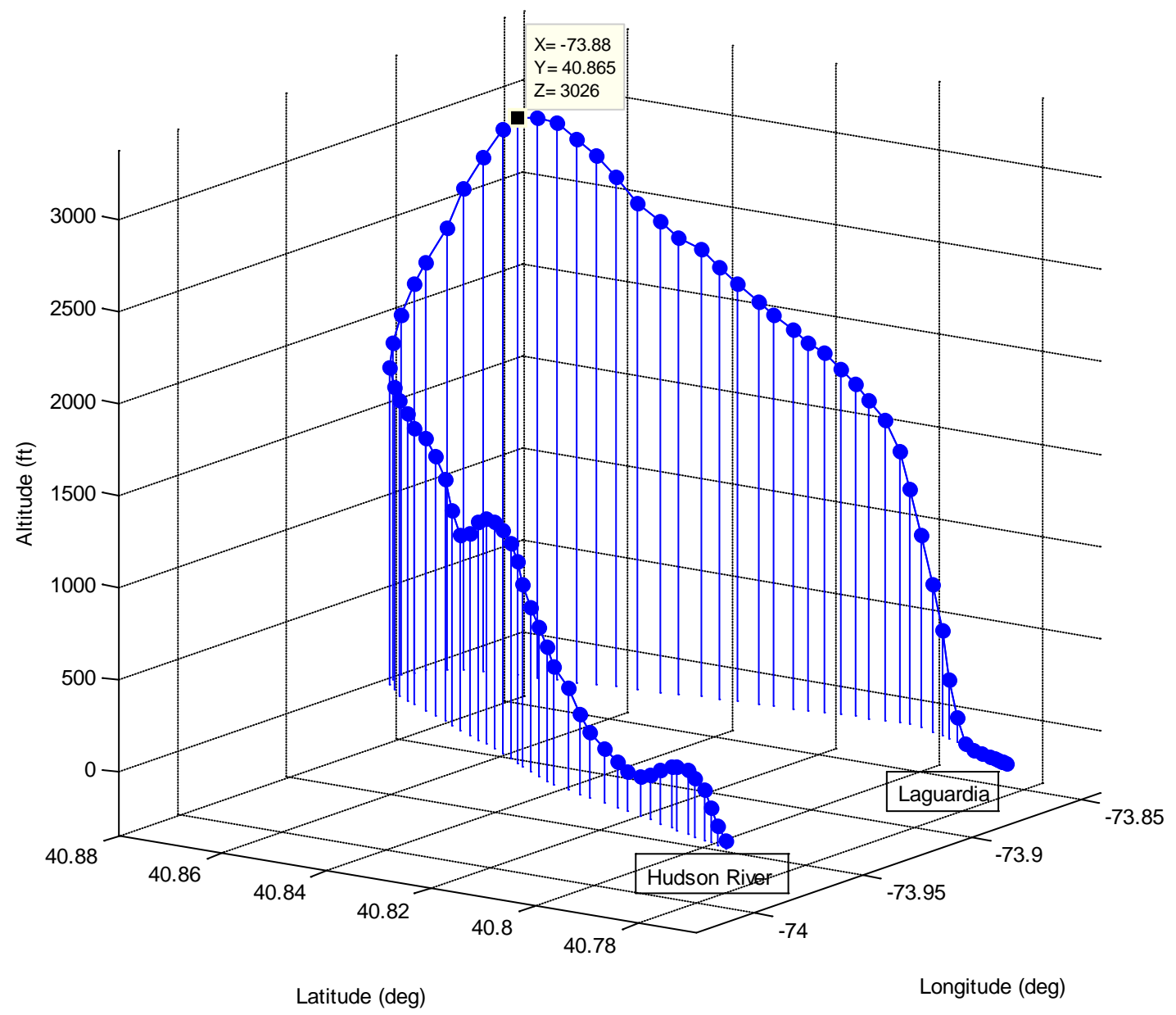

Figure 10: 3D Trajectory Profile (from Flight Data). 


\section{Adaptive Flight Planning applied to Flight 1549}

We applied our adaptive flight planning algorithm to the Flight 1549 loss-of-thrust situation to evaluate its performance in a real-world case study. We assumed a 160 knot glide, with steady 13.4 knot winds at heading 320 as described above. We presumed a best glide ratio of $2.5 \mathrm{~nm}$ per 1000 feet vertical descent, consistent with data from the NTSB accident docket reports. The AFP steepens the minimum descent angle during turns in accordance with basic steady flight equations and adds a margin of safety to glide path when possible. Bank angle for turns was set at 35 degrees, comparable to what the US Airways pilot commanded during the primary turn to the Hudson. Our turn radius was smaller, however, due to our lower glide speed, and computed as a function of atmospheric density. We presumed a weight of $151000 \mathrm{lbs}$ and wing surface area of 122.4 square meters. We did not find drag coefficients thus estimated values producing climb and turn results consistent with those expected for the A320. We ran a series of tests in which we varied initial coordinates, beginning with the latitude, longitude, altitude labeled in Figure 10 and continuing with each set of GPS coordinates, separated by 4 second intervals, until our AFP was no longer able to identify a feasible landing trajectory to a runway. ${ }^{\dagger}$ Note that our AFP has no model of terrain or other geographic features (e.g., the Hudson), so if it cannot find a trajectory to any feasible runway, no assistance is available.

Table 1 shows the runways identified as reachable by the Landing Site Search module and determined to meet minimum length and width constraints for the A320. These same four runways, all at LaGuardia airport from which Flight 1549 departed, were identified as reachable for the three initial states for which the AFP found a solution, denoted ( $\mathrm{t}+4 \mathrm{sec}),(\mathrm{t}+8 \mathrm{sec})$, and $(\mathrm{t}+12 \mathrm{sec})$, where $\mathrm{t}$ represents the maximum-altitude time point in the GPS FDR data. At data point $(\mathrm{t}+16)$ the aircraft has descended and turned further away from LaGuardia. The AFP therefore can no longer find a feasible emergency landing trajectory with an acceptable glide flight path angle even with a minimum-length Dubins solution. As shown in Table 1, the distinguishing feature between the four available runways is wind. The top-ranked runway, LaGuardia (LGA) 31, has approximately a headwind and no crosswind given the wind direction of 320. Runway 13 is ranked next since it has no crosswind but a mild tailwind. LGA runways 4 and 22 both experienced a crosswind, with 4 ranked slightly ahead due to its slightly higher headwind component. Based on Table 1, in all our test cases the AFP will first attempt to identify a landing trajectory for LGA 31, followed by 13, 4, then 22 if necessary.

Table 1: Reachable Runway Utilities (some matching utility values not shown).

\begin{tabular}{|c|c|c|c|c|c|c|c|}
\hline Airport & Runway & Elevation & Length & Width & Headwind & Crosswind & Utility \\
\hline LGA & 31 & $22^{\prime}$ & $7000^{\prime}$ & $150^{\prime}$ & 1 & 1 & $\mathbf{0 . 9 9 2 5}$ \\
\hline LGA & 13 & $22^{\prime}$ & $7000^{\prime}$ & $150^{\prime}$ & 0 & 1 & $\mathbf{0 . 9}$ \\
\hline LGA & 4 & $22^{\prime}$ & $7000^{\prime}$ & $150^{\prime}$ & 0.588 & 0 & $\mathbf{0 . 8 5 8 8}$ \\
\hline LGA & 22 & $22^{\prime}$ & $7000^{\prime}$ & $150^{\prime}$ & 0.412 & 0 & $\mathbf{0 . 8 4 1 2}$ \\
\hline
\end{tabular}

Figures 11 and 12 show the emergency landing trajectory generated by the AFP for case $t+4$ seconds, initiated at state longitude, latitude, altitude, true heading $\}=\left\{-73.88000^{\circ}, 40.86500^{\circ}, 3026 \mathrm{ft}, 12.9^{\circ}\right\}$. As shown, the AFP is able to build a landing trajectory to LGA 31, the top-ranked runway. Although the aircraft doesn't have a long final approach, it will be able to land with a headwind, a priority given that the LGA runways are only 7000 feet long and use of thrust reversers was not an option. Figures 13 and 14 show the next case, $t+8$ seconds, with the emergency landing trajectory executed a mere four seconds after the $t+4$ seconds case. Initial state is $\left\{-73.88056^{\circ}, 40.86778^{\circ}\right.$, $2949 \mathrm{ft}, 9.4^{\circ}$. Although the aircraft is less than one hundred feet lower in altitude, it also is further from LGA. As

\footnotetext{
† The GPS latitude and longitude data was offset by one second in the FDR but this difference is not significant for our computations. Our choice of the four second separation between AFP runs was governed by the four second interval between FDR data points.
} 
shown, LGA 31 is not reachable, but LGA 13 can be reached. Since LGA 13 can be reached easily, a 1nm final approach segment is inserted to enhance safety. LGA 13 has minimal crosswind but it does have a significant fraction of the 13.4 knot wind as a tailwind. In the final $t+12$ sec case, the initial state $\left\{-73.8819^{\circ}, 40.8711^{\circ}, 2789^{\prime}\right.$, $\left.1.3^{\circ}\right\}$ has nearly a due North heading away from LGA and has over a $200 \mathrm{ft}$ loss in altitude from the original ( $\mathrm{t}+4$ sec) point only eight seconds earlier. Both LGA 31 and LGA 13 are deemed infeasible by the AFP. The only reachable runway is LGA 22, and as shown in Figures 15 and 16 the margin is not great, concluded from the minimal final approach prior to touchdown. As shown through this progression of results, response time is of the essence for Flight 1549. Our LSS and WGA algorithms together require under a second to execute thereby providing ample opportunity for a pilot and ATC to approve and initiate the provided plan.

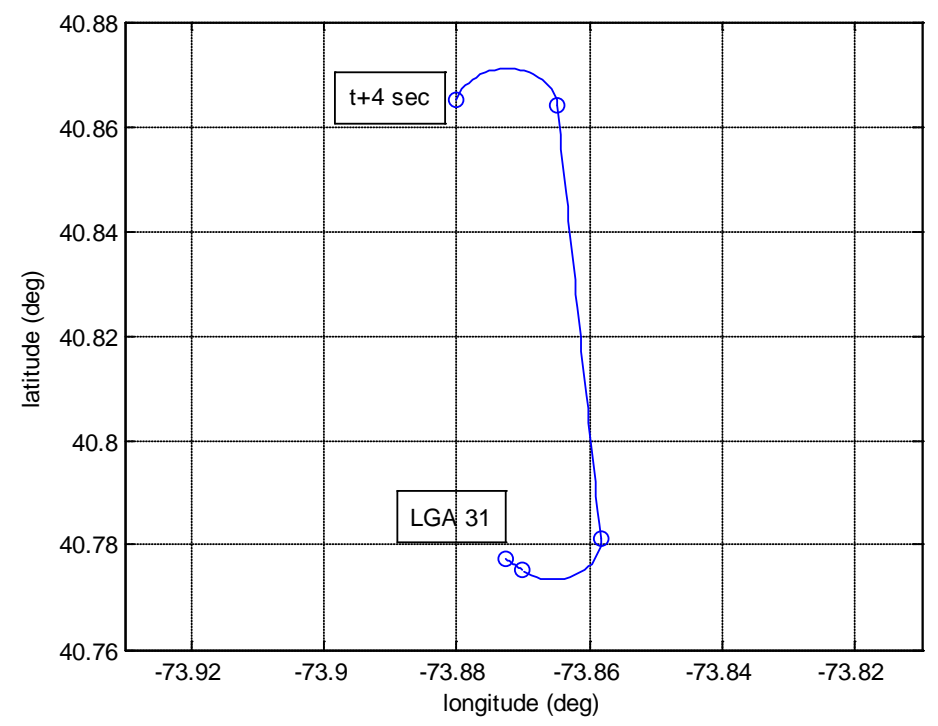

Figure 11: AFP Landing Trajectory to LGA 31 (2D): Loss-of-thrust detection +4 seconds

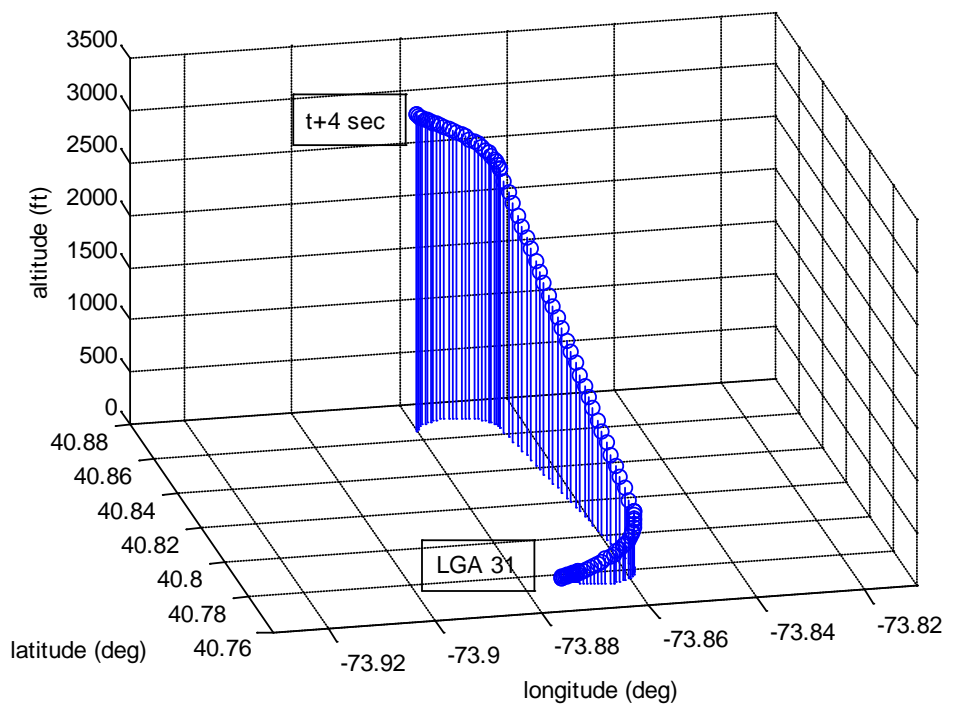

Figure 12: AFP Landing Trajectory to LGA 31 (3D): Loss-of-thrust detection + 4 seconds. 


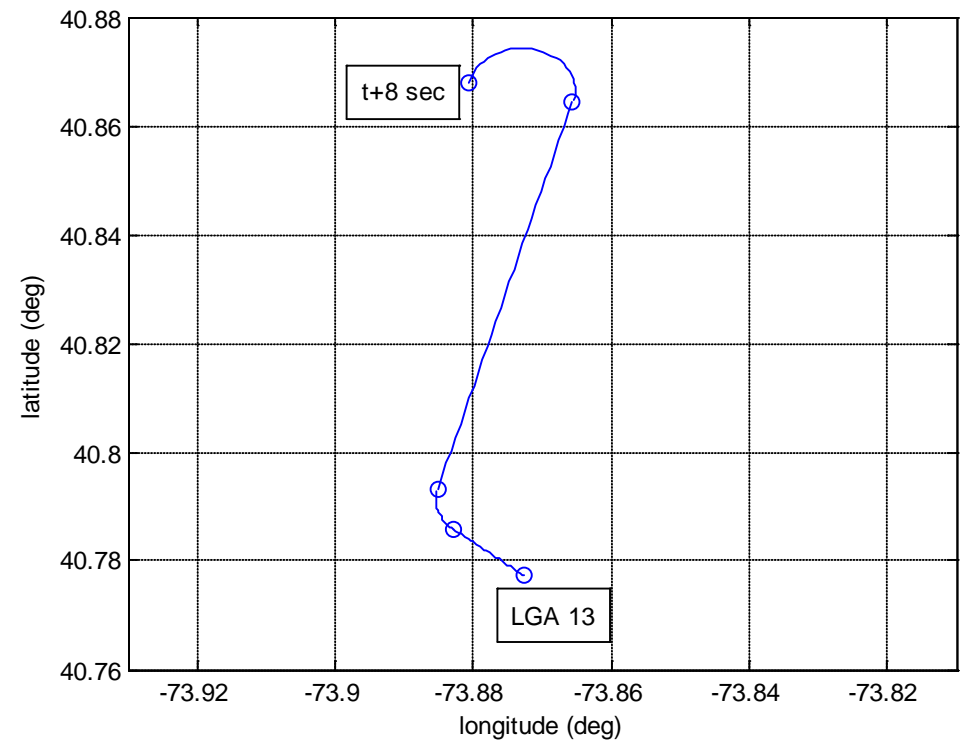

Figure 13: AFP Landing Trajectory to LGA 13 (2D): Loss-of-thrust detection + 8 seconds

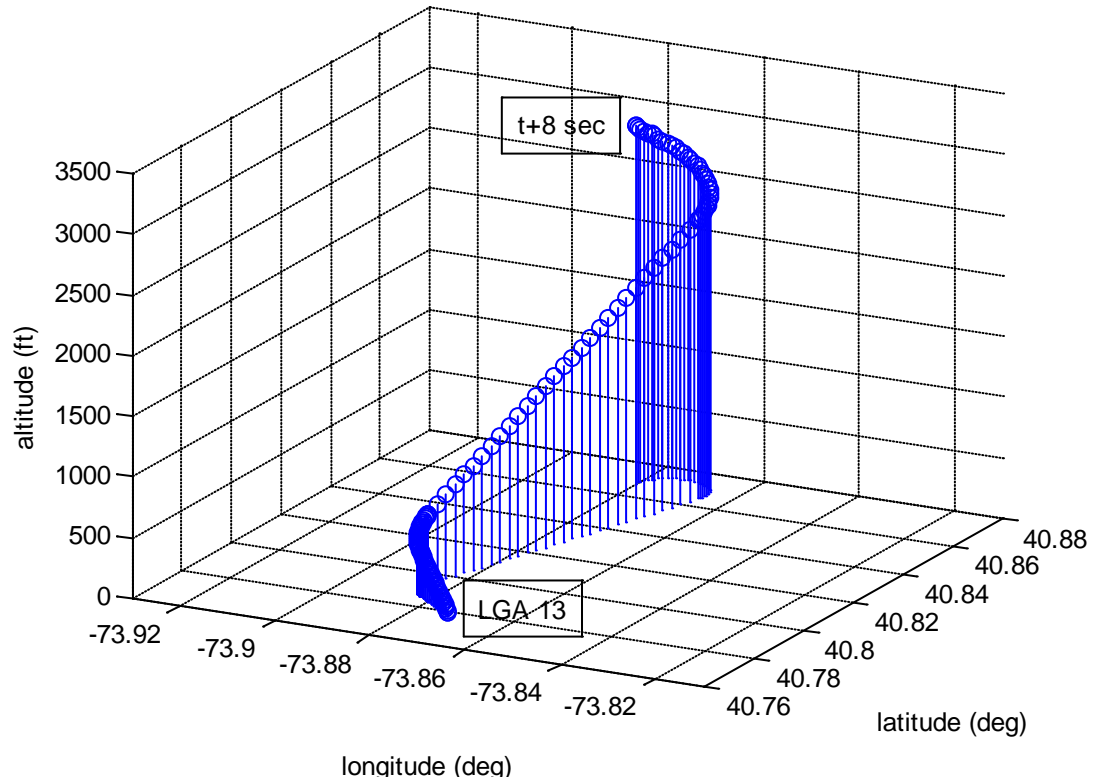

Figure 14: AFP Landing Trajectory to LGA 13 (3D): Loss-of-thrust detection +8 seconds 


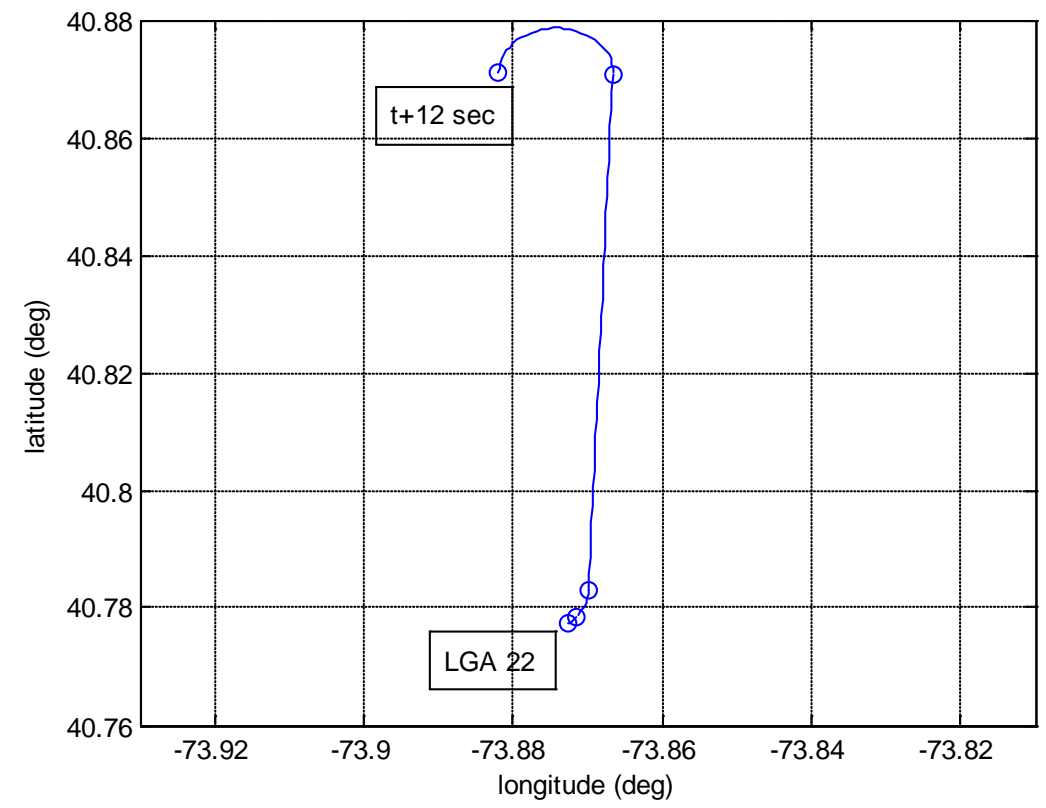

Figure 15: AFP Landing Trajectory to LGA 22 (2D): Loss-of-thrust detection + 12 seconds

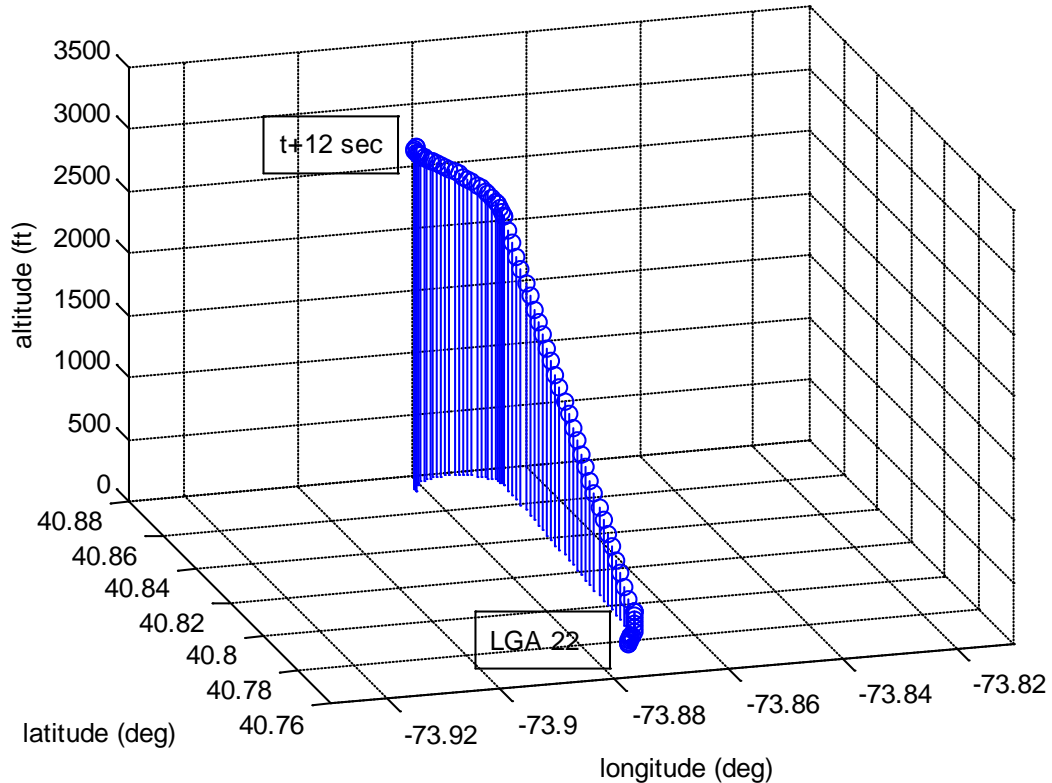

Figure 16: AFP Landing Trajectory to LGA 22 (3D): Loss-of-thrust detection + 12 seconds

\section{AFP Automation Aids: Beyond the Cockpit}

Although pilot and aircraft have priority during an emergency, lack of air traffic controller (ATC) situational awareness can still impact efficiency in handling. The adaptive or emergency flight planning algorithm we will describe below has the ability to inform the controller as well as the pilot via emergency data transfer between aircraft and air traffic control (ATC). Traditional verbal communications with ATC are potentially incomplete 
during an emergency situation because the pilots are busy assessing the cause and extent of the emergency, dealing with flying the aircraft, and keeping the cabin crew informed to make necessary preparations. Furthermore air traffic controllers are habituated to use standard approach corridors, especially through high density airspace, and if they do not fully understand the nature of an emergency they may issue vectors that differ significantly from an optimal return path, be it an engine-out glide or an arcing approach dictated by a flight control failure. The ditching of USAir Flight 1549 into the Hudson River is a perfect example of the difference an automated emergency path planning system with ATC data downlink capability could make for air traffic controllers and pilots alike.

The Flight 1549 case is highlighted by an extremely experienced pilot combined with New York Tracon air traffic controllers who are reputed to be some of the best in the world. Despite these advantages, the decision process was not an easy one, and currently available technology could have helped significantly. A digital emergency data link would have helped with even the first report of the situation, for which the "mayday mayday mayday" was cut off by another transmission on the same frequency. The controller still quickly understood the gravity of the situation, but this event highlights the loss of potentially valuable information when using verbal communications. Faced with total engine failure the captain first elected, as would most pilots, to attempt a return to the departure airport. He started a left turn and was subsequently given a radar vector of 220 degrees (see communications in Table 2 below) for the return to LaGuardia, although continuing the left turn to 180 degrees would be a more direct route to the approach end of runway 13 at LaGuardia (LGA 13). The controller suggests the optimal landing runway for this return path, runway 13, but the pilot then declares "unable." The reason the pilot is unable, namely insufficient gliding range, does not register with the controller who comes back with instructions for a longer route, making left traffic for runway 31 (LGA 31). He then notes that runway four is available with left traffic, though again this approach would be longer than coming directly in to runway 13. At that point the pilot states he is "not sure we can make any runway" and asks for controller assistance in finding an airport he can reach, and mentions Teterboro, New Jersey. The controller asks "you wanna try and go to Teterboro?" and the pilot replies "yes," but 23 seconds later states "we can't do it" followed by "we're gonna be in the Hudson." As shown above, the duration of this interchange was longer than the maximum delay before the aircraft would have needed to begin an emergency approach to LaGuardia. Lack of hard data on which runways could or could not be reached, and how, clearly affected the difficult choice to land this aircraft on the Hudson River.

Datalink availability for adaptive flight plans can deliver and present valuable and consistent information in real time to pilots and air traffic controllers in the event of an emergency such as this. Human factors concerns will need to be addressed in future work, but our focus in this presentation is with the real-time automation aid itself as well as advocating communication of this significant data to all who can benefit from it. We propose a system that communicates in two modes: Mode 1 is the onboard computer calculating an emergency trajectory and immediately displaying the recommended path to a preferred, reachable landing site and presenting concise data on reserve altitude or other parameters that would give a level of confidence that the runway will be reached safely. In the USAir 1549 example this would be telling the pilot "you can make it back to LaGuardia if you follow this path, right now, and have a certain excess altitude at the runway threshold (at best glide)", translating to an energy buffer to account for unexpected disturbances. In the event of a computer-detected total loss of thrust, given by throttle levers at a nominal position with indications of no thrust produced, detection of the event followed by computation of a glide path to landing would be completed in under a second using our simple AFP strategy; this data would not only be displayed immediately to the pilots, but would also be down-linked to ATC. This would allow ATC to immediately identify (1) the existence of an emergency at all applicable ATC stations in the area, (2) the nature of the emergency, (3) potential path(s) that need to be cleared of other traffic. The pilot would then accept (or reject) the landing plan, but this execution can be fast, based on information provided to the pilot and based on nearimmediate indication of intentions to ATC. 
Table 2: Selected Transcripts of CVR and ATC Communication Data

\begin{tabular}{|c|c|c|}
\hline TIME & SOURCE & TRANSCRIPTION \\
\hline$\overline{15: 27: 10.4}$ & $\overline{\text { HOT-1 }}$ & birds. \\
\hline $15: 27: 11.4$ & CAM & [sound of thump/thus(s) followed by shuddering sound] \\
\hline $15: 27: 13$ & CAM & [sound similar to decrease in engine noise/frequency begins] \\
\hline $15: 27: 15$ & HOT-1 & we got one roll- both of 'em rolling back. \\
\hline $15: 27: 18$ & CAM & [rumbling sound begins and continues until approximately 15:28:08] \\
\hline 15:27:18.5 & HOT-1 & ignition, start. \\
\hline $15: 27: 21.3$ & HOT-1 & I'm starting the APU. \\
\hline $15: 27: 23.2$ & HOT-1 & my aircraft. \\
\hline $15: 27: 24$ & HOT-2 & your aircraft. \\
\hline $15: 27: 25$ & CAM & [sound similar to electrical noise from engine igniters begins] \\
\hline $15: 27: 28$ & HOT-1 & get the QRH... [Quick Reference Handbook] loss of thrust on both engines. \\
\hline $15: 27: 32.9$ & RDO-1 & $\begin{array}{l}\text { mayday mayday mayday. uh this is uh Cactus fifteen thirty nine hit birds, we've lost thrust in } \\
\text { both engines we're turning back towards LaGuardia. }\end{array}$ \\
\hline $15: 27: 42$ & DEP L116 & $\begin{array}{l}\text { ok uh, you need to return to LaGuardia? turn } \\
\text { left heading of uh two two zero. }\end{array}$ \\
\hline $15: 27: 46$ & RDO-1 & two two zero. \\
\hline $15: 27: 49$ & DEP L116 LL & \{controller land line $\}$ tower stop your departures we got an emergency returning \\
\hline $15: 27: 53$ & LGA LL & \{controller land line $\}$ who is it \\
\hline $15: 27: 54$ & DEP L116 LL & $\begin{array}{l}\text { \{controller land line\} it's fifteen twenty nine he ah bird strike he lost all engines he lost the } \\
\text { thrust in the engines he is returning immediately }\end{array}$ \\
\hline 15:27:59 & LGA LL & \{controller land line\} cactus fifteen twenty nine which engines \\
\hline 15:28:01 & DEP L116 LL & \{controller land line $\}$ he lost thrust in both engines he said \\
\hline 15:28:03 & LGA LL & \{controller land line got it \\
\hline 15:28:05 & DEP L116 & $\begin{array}{l}\text { Cactus fifteen twenty nine, if we can get it for you do you want to try to land runway one } \\
\text { three? }\end{array}$ \\
\hline $15: 28: 10.6$ & RDO-1 & we're unable. we may end up in the Hudson. \\
\hline $15: 28: 25$ & HOT-1 & yeah. the left one's coming back up a little bit. \\
\hline $15: 28: 31$ & DEP & $\begin{array}{l}\text { arright Cactus fifteen forty nine its gonna be left } \\
\text { traffic for runway three one. }\end{array}$ \\
\hline $15: 28: 35$ & RDO-1 & unable. \\
\hline 15:28:36 & DEP L116 & okay, what do you need to land? \\
\hline $15: 28: 46$ & DEP L116 & $\begin{array}{l}\text { Cactus fifteen (twenty) nine runway four's available } \\
\text { if you wanna make left traffic to runway four. }\end{array}$ \\
\hline $15: 28: 49.9$ & RDO-1 & $\begin{array}{l}\text { I'm not sure we can make any runway. uh what's over to our right anything in New Jersey } \\
\text { maybe Teterboro? }\end{array}$ \\
\hline 15:29:02 & DEP L116 & you wanna try and go to Teterboro? \\
\hline 15:29:03 & RDO-1 & yes. \\
\hline 15:29:11 & PA-1 & this is the Captain brace for impact. \\
\hline $15: 29: 21$ & $\begin{array}{l}\text { DEP } \\
\text { L116 }\end{array}$ & $\begin{array}{l}\text { Cactus fifteen twenty nine turn right two eight } \\
\text { zero, you can land runway one at Teterboro. }\end{array}$ \\
\hline $15: 29: 25$ & RDO-1 & we can't do it. \\
\hline $15: 29: 25$ & HOT-1 & go ahead, try number one. \\
\hline $15: 29: 27$ & DEP L116 & kay which runway would you like at Teterboro? \\
\hline $15: 29: 28$ & RDO-1 & we’re gonna be in the Hudson. \\
\hline 15:29:33 & DEP L116 & I'm sorry say again Cactus? \\
\hline $15: 29: 44$ & HOT-2 & no relight. \\
\hline $15: 30: 03$ & HOT-2 & two hundred fifty feet in the air. \\
\hline $15: 30: 22$ & DEP L116 & $\begin{array}{l}\text { Cactus fifteen twenty nine if you can uh....you got uh runway uh two nine available at Newark } \\
\text { it'll be two o'clock and seven miles. }\end{array}$ \\
\hline 15:30:38 & HOT-1 & we're gonna brace. \\
\hline $15: 30: 42$ & & impact on Hudson River as seen by pier based surveillance camera \\
\hline $15: 30: 45$ & N461SA & \{to Class B controller\} he's in the water \\
\hline
\end{tabular}

Note that, for reference in this table, impact was 15:30:42 by the NTSB animation synchronized with the surveillance camera on Pier 38 that captured the actual touchdown on the river. ${ }^{16}$ In Table 2, the following abbreviations are used: 
HOT-1 Headset microphone of Captain Sullenberger

HOT-2 Headset microphone of First Officer Skiles

CAM Cockpit Area Microphone

RDO-1 Radio Transmission of Captain Sullenberger

DEP L116 New York TRACON LaGuardia Departure Controller Position L116

LGA LaGuardia Air Traffic Control Tower

N461SA Helicopter N461SA operating in the crash area

The presence of landing path data also minimizes the need for controllers to coordinate among numerous stations via land line communications, and allows them to focus on clearing traffic or dealing with the emergency at hand. In the case of USAir 1549 the controller (who was doing a fine job and trying to offer as many alternatives as possible) would not have made the extraneous suggestion of Newark Airport while the pilots were busy trying to ditch the airplane. He also might not have suggested a 22 flight heading given the westerly component of this heading led away from LaGuardia. We believe information sharing in two modes is beneficial: the automation can share its computations with both pilot and ATC, but both would be trained to understand that recommended paths would only be executed once pilot acceptance is complete. The distinction between recommended and accepted plans could be so simple as a change in color in landing path display (e.g., from red to green), although again the emphasis in this paper is on the automation aid and its use, not on interfaces. With this relatively easy-to-implement suggestion, experienced pilots will have at their disposal in real time the information they need to make difficult decisions strongly affecting aviation safety.

\section{Conclusions and Future Work}

This paper has examined the practical application of our adaptive flight planner to the US Airways Flight 1549 lossof-thrust situation, demonstrating how this technology, if available, could have enabled a safe return to a LaGuardia runway. First, the adaptive flight planning architecture and its evolution were summarized, followed by an analysis of the Flight 1549 cockpit data recording time histories to identify pertinent features for our analysis. The adaptive flight planner was tasked with identifying emergency no-thrust landing plans for the A320 at a series of different delay times after the dual bird strike incident occurred. Our results show that LaGuardia airport runways were reachable so long as the approach is initiated within approximately sixteen seconds after the dual bird strike incident. These results also demonstrate how chances of a safe runway landing decrease as a function of delay. Our adaptive flight planning software, written in C, computes landing flight plans in under a second on a single-core PC with no changes in this work (beyond A320 parameter incorporation) from a pre-2009 implementation. With subsecond real-time response, an emergency landing plan can be presented to the pilot just as he/she is beginning to consider options, maximizing the efficiency of the decision and the subsequent response. With datalink capability, emergency flight plan information can be disseminated throughout the local air traffic network to maximize coordination efficiency. We believe this work has applicability to UAS as well as manned aircraft, providing a means by which a UAS experiencing a problem such as loss-of-thrust can automatically land safely so long as safe landing sites have been identified or made available via database.

\section{Acknowledgements}

The author would like to thank collaborator Robert Sanner from the University of Maryland for his valuable insights over the years, as well as Igor Alonso Portillo and Matthew Strube for their long-past assistance in developing the loss-of-thrust adaptive flight planner used in this paper. This research was supported in part under the NASA Aviation Safety program, Integrated Resilient Aircraft Control (IRAC) NRA Cooperative Agreement NNX08AB93A.

\section{References}


1 W. Langewiesche, Fly by Wire: The Geese, the Glide, the Miracle on the Hudson, Farrar, Staus, and Giroux, New York, 2009.

2 National Transportation Safety Board (NTSB), "Transcript - Public Hearing Day 1," Landing of USAirways Flight 1549, Airbus A320, N106US, in the Hudson River, June 9-11, 2009, URL: http://www.ntsb.gov/events/2009/Weehawken-NJ/Default.html.

3 Alonso Portillo and E. Atkins, "Adaptive Trajectory Planning for Flight Management Systems," AIAA Aerospace Sciences Meeting, Reno, Nevada, January 2002. (AIAA-2002-1073)

${ }^{4}$ E. Atkins, I. Alonso Portillo, and M. Strube, "Emergency Flight Planning applied to Total Loss of Thrust," Journal of Aircraft, AIAA, vol. 43, no. 4, pp. 1205-1216, 2006.

5 D. Kenny, D. Wright, K. Vasconcelos (eds.), “2008 Nall Report: Accident Trends and Factors for 2007,” AOPA Air Safety Foundation, Frederick, MD, 2009, URL: http://www.aopa.org/asf/publications/08nall.pdf.

${ }^{6}$ M. Strube, R. Sanner, and E. Atkins, "Dynamic Flight Guidance Recalibration after Actuator Failure," Proc. $1^{\text {st }}$ AIAA Intelligent Systems Conference, Chicago, IL, September 2004.

7 Y. Tang, E. Atkins, R. Sanner, "Emergency Flight Planning for a Generalized Transport Aircraft with Left Wing Damage," AIAA Guidance, Navigation and Control Conference and Exhibit, Hilton Head, South Carolina, August 2007.

8 Dubins, L., "On Curves of Minimal Length with a Constraint on Average Curvature and with Prescribed Initial and Terminal Positions and Tangents,” American Journal of Mathematics, Vol. 79, pp. 497-516, 1957.

${ }^{9}$ H. J. Choi and E. M. Atkins, “An Analytic Trajectory Planner for Aircraft with Severe Damage or Failures," AIAA Infotech@Aerospace Conference, Seattle, Washington, April 2009.

${ }^{10}$ T. L. Chen and A. R. Pritchett, "Development and Evaluation of a Cockpit Decision Aid for emergency Trajectory Generation,” Journal of Aircraft, vol. 38, No. 5, September-October 2001, pp. 935-943.

${ }^{11}$ T. Fan, Hyams, D. S., Kuchar, J.K., "Study of In-Flight Replanning Decision Aids," AIAA Guidance Navigation and Control Conference, Boston, MA, 1998.

${ }^{12}$ Federal Aviation Administration (FAA), USAirways 1549 Accident and Incident Data, 2009, URL: http://www.faa.gov/data_research/accident_incident/1549/.

${ }^{13}$ National Transportation Safety Board (NTSB) Docket Management System, "Flight Data Recorder 10B Attachment 1 - Tabular Data," Docket ID 47230, June 9, 2009 (Public Release Date), URL: http://www.ntsb.gov/Dockets/Aviation/DCA09MA026/default.htm.

${ }^{14}$ National Transportation Safety Board (NTSB) Docket Management System, "Aircraft Performance 13 - Factual Report of Group Chairman," Docket ID 47230, June 9, 2009 (Public Release Date), URL: http://www.ntsb.gov/Dockets/Aviation/DCA09MA026/default.htm.

${ }^{15}$ National Transportation Safety Board (NTSB) Docket Management System, "Cockpit Voice Recorder 12 Factual Report of Group Chairman," Docket ID 47230, June 9, 2009 (Public Release Date), URL: http://www.ntsb.gov/Dockets/Aviation/DCA09MA026/default.htm.

${ }^{16}$ National Transportation Safety Board (NTSB) Docket Management System, "Water Landing of U.S. Airways Fight 1549, Airbus A320, N106US, in the Hudson River”, URL: http://www.ntsb.gov/events/2009/WeehawkenNJ/AnimationDescription.htm 